\title{
Modulatory effects of perindopril on cisplatin-induced nephrotoxicity in mice: Implication of inflammatory cytokines and caspase- 3 mediated apoptosis
}

NAIF ALJUHANI

RAED S. ISMAIL ${ }^{2}$

MOHAMMED S. EL-AWADY1,3

MEMY H. HASSAN ${ }^{1,2, *}$

${ }^{1}$ Department of Pharmacology and Toxicology, College of Pharmacy Taibah University, Al-Madinah Al-Munawwarah, Saudi Arabia

${ }^{2}$ Department of Pharmacology and Toxicology, Faculty of Pharmacy Al-Azahr University, Cairo, Egypt

${ }^{3}$ Department of Pharmacology and Toxicology, Faculty of Pharmacy Mansoura University, Mansoura, Egypt
Accepted November 18, 2019

Published online December 10, 2019
Cisplatin-induced nephrotoxicity limits its anticancer effectiveness, thus this study's aim was to assess the potential modulatory effect of perindopril on cisplatin-induced nephrotoxicity and to elucidate the possible underlying mechanisms. Renal dysfunction was induced in mice by a single injection of cisplatin (10 $\mathrm{mg} \mathrm{kg}^{-1}$, i.p.) and perindopril was administered orally ( $2 \mathrm{mg} \mathrm{kg}^{-1}$, once daily) for 5 days. Perindopril remarkably ameliorated cisplatin-induced perturbations in renal histology, renal levels of tumor necrosis factor-alpha, interleukin-6 and interleukin-10, apoptosis-regulating protein expressions ( $\mathrm{Bax}$ and $\mathrm{Bcl} 2$ ), and partially normalized $\mathrm{Bax}$ to $\mathrm{Bcl} 2$ ratio and active caspase 3 protein expression. Conversely, perindopril had no significant effect on cisplatin-induced elevations in serum creatinine and urea, microalbuminuria, kidney to body weight ratio, lipid peroxidation marker, superoxide dismutase and catalase activities and reduced glutathione content. In conclusion, perindopril may be safely used with cisplatin in mice since it ameliorated cisplatin-induced histopathological changes, inflammation and apoptosis without affecting renal biomarkers or oxidative stress.

Keywords: perindopril, cisplatin, nephrotoxicity, oxidative stress, apoptosis, inflammation

Cisplatin is a chemotherapeutic drug clinically effective against various types of malignancies. However, due to frequent adverse effects including bone marrow suppression, neurotoxicity, ototoxicity, and notably nephrotoxicity, its clinical utility has been hampered (1). The major excretion route of cisplatin is renal. Cisplatin accumulates in the renal tissue resulting in necrosis of the proximal renal tubules and apoptosis in the distal nephron (2). About $30 \%$

\footnotetext{
*Correspondence, e-mail: memymahmoud@yahoo.com
} 
of patients receiving high-dose cisplatin have experienced severe renal dysfunction (3). Cisplatin has been reported to injure several renal structures including blood vessels, glomeruli, and most commonly the renal tubules (4). Clinical reports show that cisplatin-induced renal toxicity often results in acute renal failure, which is characterized by declines in renal blood flow within 3 hours of cisplatin administration and decreased glomerular filtration rate (5). Other complications, namely elevated levels of serum creatinine and blood urea nitrogen, have also been reported in both acute and chronic cisplatin-induced renal toxicity (6). Several experimental studies suggest a sequential injury pathway in cisplatin-induced renal toxicity, particularly conversion to toxic metabolites, induction of nuclear and mitochondrial DNA damage, oxidative stress and mitochondrial dysfunction, induction of inflammation and activation of apoptotic pathway $(7,8)$. Prevention of cisplatin-induced nephrotoxicity reduces complications and may allow administration of a higher dose of cisplatin with added therapeutic potential. Clinical approaches to improve cisplatin-induced-nephrotoxicity have been ongoing, however, there is no optimal protective agent. Therefore, it is pertinent to develop a therapy to limit the cisplatin-induced nephrotoxicity that might target one or more of cisplatin-nephrotoxic pathways (9). Many patients who are receiving cisplatin might be using additional drugs to control other diseases such as hypertension for which angiotensin-converting enzyme inhibitors (ACEIs) are the first-line choice. Studies on interactions between cisplatin and ACEIs drugs are limited.

Perindopril is an oral ACEI prodrug that results in decreased plasma angiotensin II level, decreased vasoconstriction, and decreased aldosterone secretion (10). Perindopril is approved for the treatment of hypertension, arterial stiffness, left ventricular hypertrophy, post-myocardial infarction and reduction of albuminuria in patients with hypertension and nephropathy or diabetes mellitus $(10,11)$. Accumulated evidence suggests the role of localized renin-angiotensin system (RAS) in the progression of different pathologies. RAS stimulation mediates oxidative and inflammatory damage, mostly via activation of NADPH oxidase and the inhibition of endothelial nitric oxide synthase $(12,13)$. Interestingly, interference with localized RAS in different animal models using ACEIs was shown to offer protective effects in the liver (14), respiratory tract (15), joints (16) and the brain (13). The aim of the present study was to examine the possible modulatory effects of perindopril on cisplatin-induced acute nephrotoxicity in mice and the potential mechanisms behind this modulation.

\section{EXPERIMENTAL}

\section{Chemicals}

Cisplatin and perindopril were purchased from Sigma-Aldrich (USA).

\section{Animals}

Male Swiss albino mice, weighing 25-30 g, were purchased and housed within the animal facility at Faculty of Pharmacy, Al-Azhar University. Animals care, treatment and sampling were executed in agree with the National Institutes of Health guide for the care and use of laboratory animals (NIH Publications No. 8023, revised 1978). 


\section{Design of the work}

Mice were randomly assigned to four groups ( 8 mice each) as follows: 1 . Control group: injected i.p. with saline ( $0.1 \mathrm{~mL}$ per $20 \mathrm{~g}$ body mass) once daily for 5 consecutive days; 2. Perindopril group: mice treated orally with perindopril ( $2 \mathrm{mg} \mathrm{kg}^{-1}$, once daily) for 5 consecutive days $(17,18)$; 3. Cisplatin group: mice injected i.p. with a single dose of cisplatin $\left(10 \mathrm{mg} \mathrm{kg}^{-1}\right)(19,20)$; 4 . Cisplatin + perindopril group: mice treated with perindopril for 5 days starting $1 \mathrm{~h}$ before cisplatin (doses as above). The first day of drug treatment was considered day zero. On day 5 , all animals were weighed, then euthanized and the serum samples were collected for the assessment of kidney functions. Urine samples were collected at end of experiment and centrifuged $\left(2000 \mathrm{~g}\right.$ at $4{ }^{\circ} \mathrm{C}$ for $\left.15 \mathrm{~min}\right)$ after which the supernatant was used for the assessment of microalbuminuria. Both kidneys from each animal were collected and weighed to calculate relative kidney mass to body mass. Portions of the kidneys were rapidly stored at $-80{ }^{\circ} \mathrm{C}$ until analyses were performed. Another portion of the kidney was placed immediately in $10 \%$ neutral buffered formalin for histopathological and immunofluorescence examinations.

\section{Evaluation of kidney status}

Serum renal biomarkers and microalbuminuria. - Sera were carefully separated from fresh blood samples and used for determination of serum kidney function markers (creatinine and urea) using colorimetric diagnostic kits according to the manufacturer's instructions (Biodiagnostic Ltd., UK). In addition, microalbuminuria was measured according to the manufacturer's instructions (Biosystems, Spain).

Histopathological evaluation of kidney. - A portion of kidney was rinsed with ice-cold saline then embedded in $10 \%$ neutral-buffered formalin for $48 \mathrm{~h}$. Samples were dehydrated by alcohol, cleared by xylol, and finally embedded in paraffin blocks. Paraffin-embedded specimens were cut into sections of 4-6 microns thickness, placed on polylysine coated slides. Slides were deparaffinized, rehydrated with ethanol, rinsed in distilled water and stained with hematoxylin and eosin (H\&E) before microscopical examination (Leica Imaging Systems, UK).

\section{Determination of oxidative stress markers}

Renal tissues were weighed and homogenized $(1: 10, \mathrm{~m} / \mathrm{V})$ in phosphate-buffered saline ( $\mathrm{pH} 7.4)$, then centrifuged $\left(2000 \mathrm{~g}\right.$ at $\left.4{ }^{\circ} \mathrm{C}\right)$ for $15 \mathrm{~min}$ and the supernatant was used to measure oxidative stress biomarkers. Renal content of malonaldehyde (MDA), reduced glutathione (GSH), superoxide dismutase (SOD) and catalase (CAT) were evaluated in the whole tissue homogenate and normalized to the protein content in each sample using commercial kits (Bio-Diagnostics, Egypt).

\section{Measurement of renal tumor necrosis factor-alpha (TNF- $\alpha$ ), interleukin-6 (IL-6)} and interleukin-10 (IL-10)

Supernatants of renal tissues homogenates were used to measure TNF- $\alpha$ using Mouse TNF- $\alpha$ ELISA Kit (Sigma-Aldrich Co, USA), IL-6 using mouse IL-6 ELISA kit (RayBiotech, Inc., USA) and IL-10 using mouse IL-10 ELISA kit (Cusabio Technology LLC, USA) according to the manufacturer's instructions. 


\section{Immunofluorescent assay of renal Bax, Bcl2 and active caspase 3 proteins}

Immunofluorescent staining was performed to determine the differences in immunoreactivity intensity of $\mathrm{Bax}, \mathrm{Bcl} 2$ and Caspase 3 proteins in renal tissues collected from mice allocated to different treatment groups. Briefly, tissue sections were deparaffinized in 100 $\%$ xylene and rehydrated through a graded ethanol series. Antigen retrieval was performed by incubating the tissue sections for $20 \mathrm{~min}$ in $0.01 \mathrm{~mol} \mathrm{~L}^{-1}$ sodium citrate buffer, $\mathrm{pH}$ 6.0, in a microwave oven. Briefly, the samples were initially boiled in a microwave at $800 \mathrm{~W}$ for $3 \mathrm{~min}$, then for $7 \mathrm{~min}$ at $400 \mathrm{~W}$ to continue boiling. After cooling down for $30 \mathrm{~min}$ at room temperature $\left(25^{\circ} \mathrm{C}\right)$, the 10 -min heating procedure was repeated with fresh buffer. Next, the sections were treated with blocking buffer [1\% horse serum in PBS] for $1 \mathrm{~h}$. Tissue sections were incubated overnight at $4{ }^{\circ} \mathrm{C}$ in a humidified chamber with the primary antibodies; Bax (1: 250; Santa Cruz Biotechnology, USA), Bcl2 (1: 250; Santa Cruz Biotechnology), and Active Caspase 3 (1: 250; Santa Cruz Biotechnology). After washing, bound antibodies were detected by Texas Red labeled goat anti-mouse secondary antibodies (Thermo Fisher Scientific, USA). Nuclei were stained with DAPI and slides were mounted in Fluoromount G. The specificity of the immunoreaction was confirmed by incubation with PBS instead of the primary antibodies. The evaluation was performed by Nikon fluorescence microscope (Nikon eclipse 90i with a DS-U3 imaging system, Nikon Metrology, Inc., USA) under blue, green, and red channels. Fluorometric density analysis was performed using Image//NIH software (National Institute of Health, USA). Fluorometric intensities of nine microscopic fields with exact areas and same resolutions were measured for each tissue section. Data represented as mean $\pm \mathrm{SD}(n=8)$.

\section{Statistical analysis}

Data were presented as means \pm standard deviation (SD). Graphpad prism V5 (Graphpad Prism Software Inc., USA) was used to perform the one-way analysis of variance (ANOVA) followed by Tukey's post hoc test. Statistical significance was accepted at $p<0.05$.

\section{RESULTS AND DISCUSSION}

\section{Effect of perindopril on kidney status}

Cisplatin caused significant elevations in serum creatinine, urea and microalbuminuria by 4.6, 10.8 and 2.3 folds of control group respectively (Table I). Administration of perindopril in cisplatin-treated mice had no significant effect on renal dysfunction induced by cisplatin since the levels of serum creatinine, urea and microalbuminuria were still significantly elevated at 4.3, 11 and 2.7 folds of control group respectively (Table I).

The kidney mass to body mass ratio was significantly increased by cisplatin to 1.3 fold of the control group (Table I). Perindopril was unable to correct cisplatin-induced elevation in the ratio of kidney mass to body mass.

In addition to kidney mass to body mass ratio, histopathological examination using $H \& E$ stain revealed normocellular glomeruli and patent tubular lumen lined by cuboidal epithelium normal kidney architecture in control and perindopril groups (Fig. 1). In the cisplatin group, there was marked vacuolar alteration of the tubular epithelium with occasional tubular cystic dilatation filled with hyaline casts (Fig. 1). Cotreatment with 
N. Aljuhani et al.: Modulatory effects of perindopril on cisplatin-induced nephrotoxicity in mice: Implication of inflammatory cytokines and caspase-3 mediated apoptosis, Acta Pharm. 70 (2020) 515-525.

Table I. Effect of perindopril on cisplatin-induced changes in renal biomarkers

\begin{tabular}{ccccc}
\hline & Control & Perin & Cis & Cis + Perin \\
\hline Serum creatinine $\left(\mathrm{mg} \mathrm{dL}^{-1}\right)$ & $0.17 \pm 0.05$ & $0.13 \pm 0.04$ & $0.78 \pm 0.20^{*}$ & $0.73 \pm 0.12^{\mathrm{a}}$ \\
Serum urea $\left(\mathrm{mg} \mathrm{dL}^{-1}\right)$ & $26.33 \pm 4.18$ & $25 \pm 3.74$ & $284.33 \pm 33.60^{*}$ & $290 \pm 14.14^{\mathrm{a}}$ \\
Microalbuminuria $\left(\mathrm{mg} \mathrm{L}^{-1}\right)$ & $300 \pm 53.57$ & $221.67 \pm 23.17$ & $700 \pm 82.28^{*}$ & $800 \pm 78.99^{\mathrm{a}}$ \\
$\% \mathrm{KM} / \mathrm{BM}$ & $1.20 \pm 0.12$ & $1.21 \pm 0.10$ & $1.58 \pm 0.20^{*}$ & $1.66 \pm 0.23^{\mathrm{a}}$ \\
\hline
\end{tabular}

Renal dysfunction was induced in mice by a single cisplatin (Cis) injection (10 $\mathrm{mg} \mathrm{kg}^{-1}$, i.p.). Perindopril (Perin) was administered orally ( $2 \mathrm{mg} \mathrm{kg}^{-1}$, once daily) for 5 days starting $1 \mathrm{~h}$ before Cis injection; and then serum creatinine, serum urea, microalbuminuria and percentage of kidney mass from total body mass $(\% \mathrm{KM} / \mathrm{BM})$ were measured. Data are represented as mean $\pm \operatorname{SD}(n=8)$; ${ }^{\text {a }}$ significant difference from the control group $(p<0.05)$; using ANOVA followed by Tukey's post hoc test.

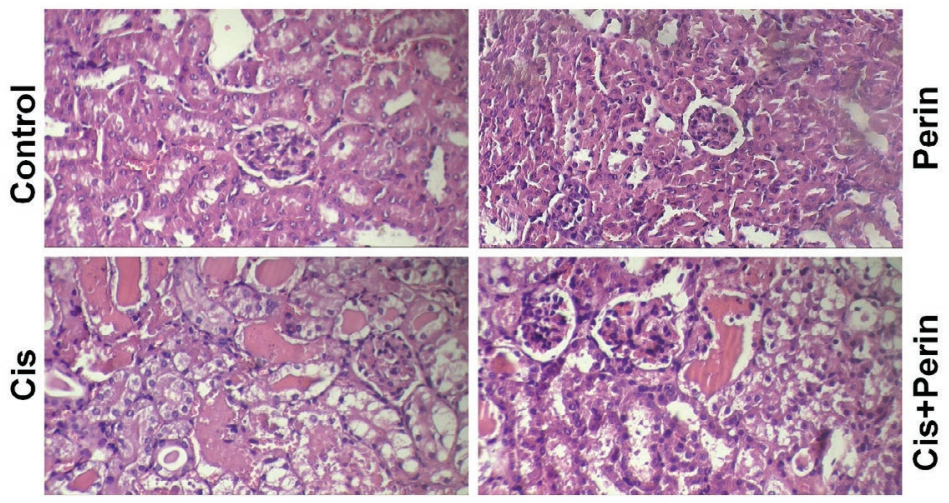

Fig. 1. Effect of perindopril on cisplatin-induced changes in kidney histopathology. Renal dysfunction was induced in mice by a single cisplatin (Cis) injection $\left(10 \mathrm{mg} \mathrm{kg}^{-1}\right.$, i.p.). Perindopril (Perin) was administered orally $\left(2 \mathrm{mg} \mathrm{kg}^{-1}\right.$, once daily) for 5 days starting $1 \mathrm{~h}$ before Cis injection. H\&E stain of renal tissue sections revealed normocellular glomeruli and patent tubular lumen lined by cuboidal epithelium normal kidney architecture in control and Perin groups. In the Cis group, marked vacuolar alteration of the tubular epithelium with occasional tubular cystic dilatation filled with hyaline casts. Cis+Perin group showed mild glomerular hypercellularity, vacuolar alteration of the tubular epithelium with occasional hyaline casts and scattered interstitial mononuclear inflammatory cell infiltrate.

perindopril caused regression of these structural changes as shown by mild glomerular hypercellularity, vacuolar alteration of the tubular epithelium with occasional hyaline casts and scattered interstitial mononuclear inflammatory cell infiltrate (Fig. 1).

Based on these results, cisplatin-induced acute nephrotoxicity was documented in this study via elevation of serum creatinine and urea in addition to microalbuminuria, histopathological perturbations of kidney tissues and kidney hypertrophy as indicated by the increase in kidney mass to body mass ratio. Interestingly, perindopril administration for 5 days had partially ameliorated cisplatin-induced nephrotoxic effect which was documented in histological analysis of renal tissue sections. Conversely, using perindopril for 
a longer period (14 days vs. 5 days in our study) in a rat model of acute cisplatin-induced nephrotoxicity showed protective effect of perindopril on cisplatin-induced serum renal biomarkers and kidney hypertrophy (21). Collectively, it is plausible that perindopril had no deteriorating effect on cisplatin-induced nephrotoxicity and it may require more time to reflect the improvement in renal functions.

\section{Effect of perindopril on oxidative stress}

Experimental evidence has indicated the basic role of oxidative stress in the pathogenesis of cisplatin-induced nephrotoxicity $(22,23)$. In our study, cisplatin had induced oxidative stress in renal tissue which is manifested by increased level of lipid peroxidation marker (MDA) to 2.0 folds of control group (Fig. 2d) and attenuation of both enzymatic (SOD and CAT) and non-enzymatic antioxidant defense (GSH) to 0.7, 0.5 and 0.5 folds of control group respectively (Fig. 2a-c). Coadministration of perindopril with cisplatin resulted in non-significant changes in these oxidative stress markers. Conversely, previous studies showed antioxidant activities for perindopril $(21,24)$. This might be due difference in disease model and treatment.

a)

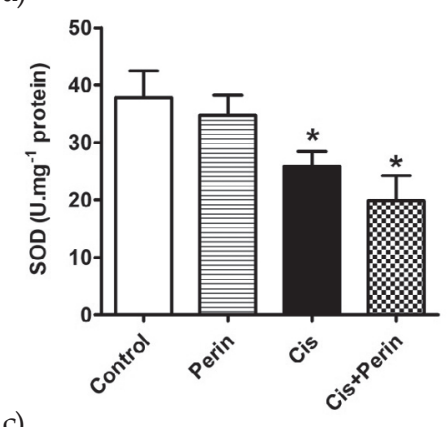

c)

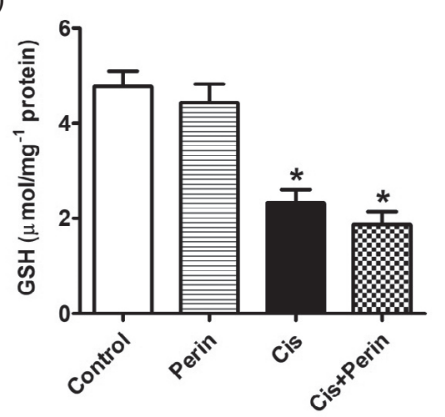

b)

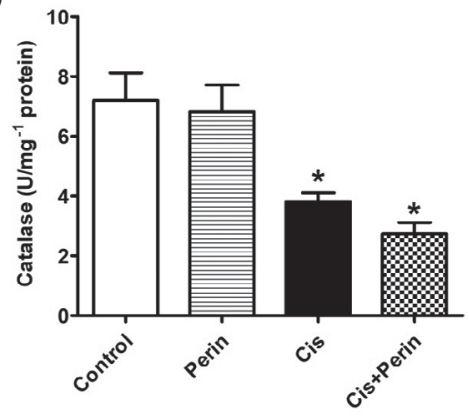

d)

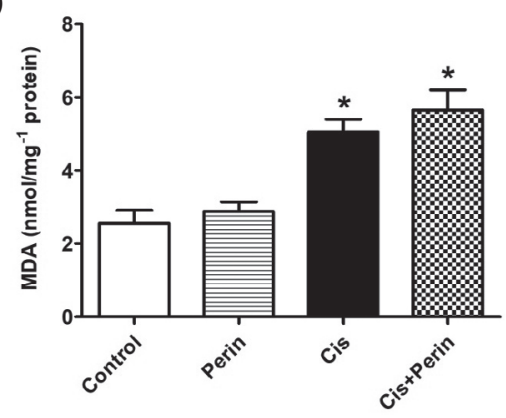

Fig. 2. Effect of perindopril on cisplatin-induced renal oxidative stress. Renal dysfunction was induced in mice by a single cisplatin (Cis) injection $\left(10 \mathrm{mg} \mathrm{kg}^{-1}\right.$, i.p.). Perindopril (Perin) was administered orally ( $2 \mathrm{mg} \mathrm{kg}^{-1}$, once daily) for 5 days starting $1 \mathrm{~h}$ before Cis injection. Renal tissue activity of: a) SOD and b) catalase in addition to c) GSH and d) MDA content were measured. Data represented as mean $\pm \mathrm{SD}(n=8) .{ }^{*}$ indicates a significant difference from the control group $(p<0.05)$; using ANOVA followed by Tukey's post hoc test. 


\section{Effect of perindopril on inflammatory markers}

In addition, induction of inflammation has been also implicated in cisplatin-induced renal tissue injury $(1,4,8)$. The current work has demonstrated that cisplatin had significantly elevated proinflammatory cytokines TNF- $\alpha$ and IL- 6 in renal tissue to 5.7 and 7.9 folds of control group respectively (Fig. 3a,b). Furthermore, cisplatin significantly decreased the renal level of the antiinflammatory cytokine IL-10 to 0.4 folds of control group (Fig. 3c). Treatment with perindopril ameliorated cisplatin-induced inflammatory pathway as indicated by the decrease in the levels of TNF- $\alpha$ and IL- 6 to 2.3 and 3.6 folds respectively and the elevation of IL-10 to 1.6 folds of control group value. Perindopril treatment in control mice had no significant effect on these inflammatory cytokines.

a)

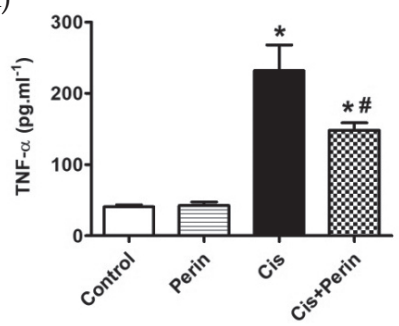

b)

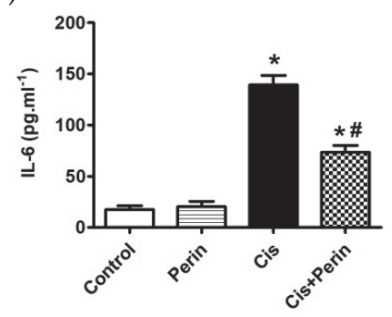

c)

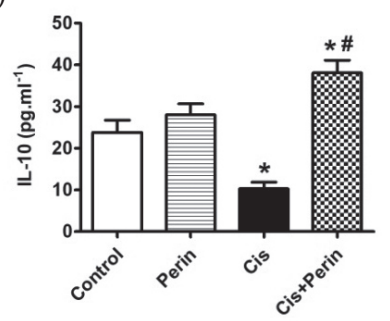

Fig. 3. Effect of perindopril on cisplatin-induced changes in renal levels of TNF- $\alpha$, IL-6 and IL-10. Renal dysfunction was induced in mice by a single cisplatin (Cis) injection (10 $\mathrm{mg} \mathrm{kg}^{-1}$, i.p.). Perindopril (Perin) was administered orally ( $2 \mathrm{mg} \mathrm{kg}^{-1}$, once daily) for 5 days starting $1 \mathrm{~h}$ before Cis injection; and then: a) TNF- $\alpha$ b) IL-6 and c) IL-10 were measured in renal tissue total homogenate. Data represented as mean $\pm \mathrm{SD}(n=8)$. *or \# indicates a significant difference from control or Cis groups respectively $(p<0.05)$; using ANOVA followed by Tukey's post hoc test.

It is documented that the induction of oxidative stress could induce inflammation of somatic cells $(25,26)$. However, in our study, perindopril alleviated cisplatin-induced inflammation without affecting cisplatin-induced oxidative stress, suggesting that the antiinflammatory effect of perindopril is independent from its antioxidant effect.

\section{Effect of perindopril on markers of apoptosis}

Both inflammation and oxidative stress have been associated with caspase-dependent renal cellular apoptosis $(25,27-29)$. Our study indicated that cisplatin administration has significantly increased the expression of the proapoptotic Bax protein 4.8 folds of control group (Fig. 4a and 4c) and significantly decreased anti-apoptotic protein Bcl-2 level to 0.3fold of control group (Fig. $4 \mathrm{~b}$ and $4 \mathrm{~d}$ ) and hence, the $\mathrm{Bax}$ to $\mathrm{Bcl} 2$ ratio was significantly increased to 3.6 folds of control (Fig. 4e). Increased Bax to Bcl2 ratio may favor the release of cytochrome $\mathrm{c}$ and could have led to the significant increase in active caspase- 3 protein expression in renal tissues (30-32), which was confirmed by our results whereas, cisplatin had induced a significant increase in the expression of active caspase 3 to 14.32 folds of control (Fig. 5a,b). These events could significantly contribute to renal cell death, which 
was further confirmed by histopathological investigation, changes in renal to body mass ratio and reduced renal function.

Interestingly, coadministration of perindopril with cisplatin significantly has decreased the expression of Bax and caspase- 3 proteins to 2.5 and 7.0 folds of control respectively and has increased the antiapoptotic protein Bcl 2 to 0.4 folds of control and remarkably normalized BAX to Bcl2 ratio, highlighting its abatement on apoptotic activity and reinforcing its potential protective effect against cisplatin-induced renal injury.

It is worth mentioning that our study examined the potential interaction between cisplatin and perindopril in a murine model. Although both drugs are commonly used in

a)

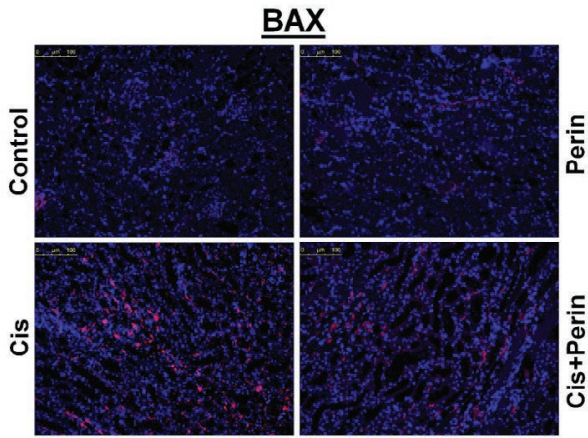

b)

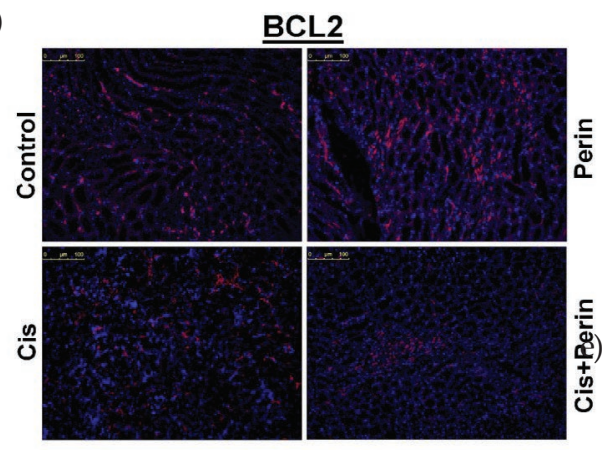

c)

d)
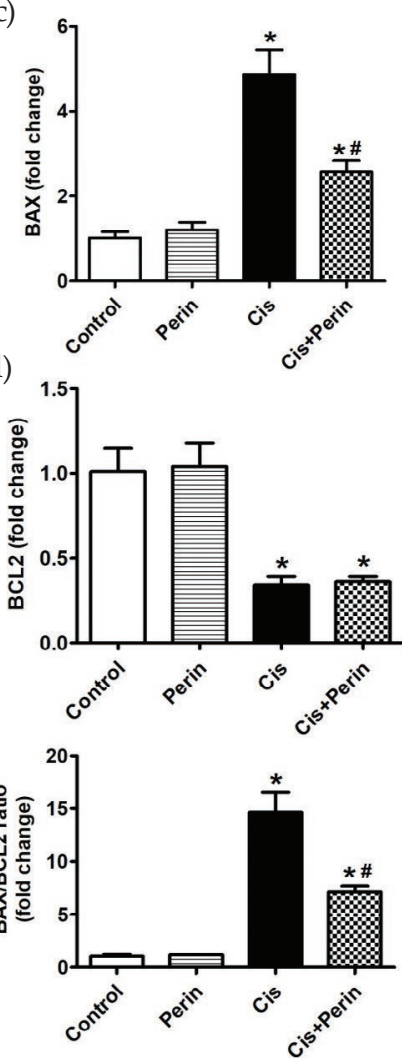

Fig. 4. Effect of perindopril on cisplatin-induced changes in the expression of renal BAX and BCL2 proteins. Renal dysfunction was induced in mice by a single cisplatin (Cis) injection (10 mg kg-1, i.p.). Perindopril (Perin) was administered orally $\left(2 \mathrm{mg} \mathrm{kg}^{-1}\right.$, once daily) for 5 days starting $1 \mathrm{~h}$ before Cis injection; and then BAX and BCL2 were measured. a) representative BAX immunofluorescence images, b) representative BCL2 immunofluorescence images, c) BAX quantification, d) BCL2 quantification, e) ratio of BAX to BCL2. The fluorometric intensity of at least nine microscopic fields was measured for each tissue section. Data represented as mean $\pm \operatorname{SD}(n=8) .{ }^{*}, \#$ indicate a significant difference from control and Cis groups respectively $(p<0.05)$; using ANOVA followed by Tukey's post hoc test. 
a)

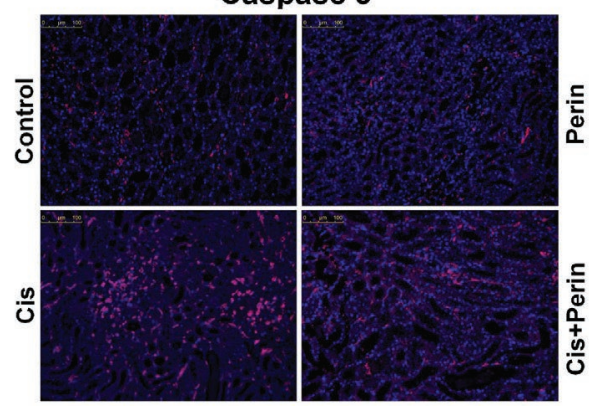

b)

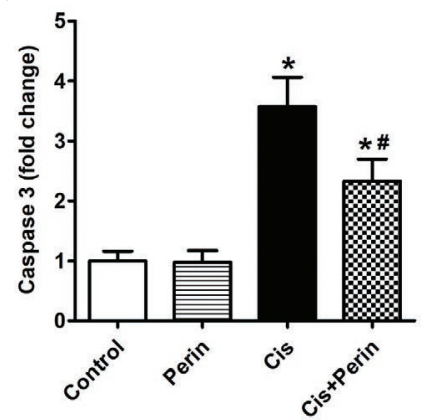

Fig. 5. Effect of perindopril on cisplatin-induced changes in renal caspase 3 protein expression. Renal dysfunction was induced in mice by a single cisplatin (Cis) injection $\left(10 \mathrm{mg} \mathrm{kg}^{-1}\right.$, i.p.). Perindopril (Perin) was administered orally $\left(2 \mathrm{mg} \mathrm{kg}^{-1}\right.$, once daily) for 5 days starting $1 \mathrm{~h}$ before Cis injection; and then Caspase 3 was measured. a) representative Caspase 3 immunofluorescence images, b) Caspase 3 quantification. Data represented as mean $\pm \mathrm{SD}(n=8)$. *, \# indicates a significant difference from control and Cis groups respectively $(p<0.05)$; using ANOVA followed by Tukey's post hoc test.

clinical situations, only a single study in a different model has examined this interaction (21), possibly during our study timeframe. The underlying mechanism behind this interaction was partially elucidated in our study including the amelioration of cisplatin-induced inflammation and apoptosis of renal cells. However, oxidative stress was not affected by perindopril which is in contrast with the previously mentioned study (21). Further studies are required on this interaction using a different animal model and different dose levels for longer duration to gain more data.

\section{CONCLUSIONS}

Perindopril may be safely used with cisplatin in mice. Perindopril ameliorated cisplatin-induced acute renal injury via abrogation of cisplatin-induced inflammation in renal cells and apoptosis without affecting oxidative stress or renal biomarkers.

Acknowledgments. - We are deeply thankful to Dr. Adel Bakeer Kholoussy, Professor of Pathology, Faculty of Medicine, Cairo University, Egypt, and his highly respected laboratory team for their invaluable contribution to the histopathological examination part of this work.

Abbreviations. - ACEI, angiotensin-converting enzyme inhibitor; ANOVA, one-way analysis of variance; BAX, Bcl2 Associated X protein; Bcl2, B-cell lymphoma 2 protein; CAT, catalase; GSH, reduced glutathione; H\&E, hematoxylin and eosin; IL-6, interleukin-6; IL-10, interleukin-10; MDA, malondialdehyde; RAS, renin-angiotensin system; SD, standard deviation; SOD, superoxide dismutase; TNF- $\alpha$, tumor necrosis factor-alpha.

\section{REFERENCES}

1. S. Dasari and P. B. Tchounwou, Cisplatin in cancer therapy: molecular mechanisms of action, Eur. J. Pharmacol. 740 (2014) 364-378; https://doi.org/10.1016/j.ejphar.2014.07.025

2. I. Arany and R. L. Safirstein, Cisplatin nephrotoxicity, Semin. Nephrol. 23 (2003) 460-464; https:// doi.org/10.1016/S0270-9295(03)00089-5 
3. A. Shiraishi, K. Sakumi and M. Sekiguchi, Increased susceptibility to chemotherapeutic alkylating agents of mice deficient in DNA repair methyltransferase, Carcinogenesis 21 (2000) 1879-1883; https://doi.org/10.1093/carcin/21.10.1879

4. N. Pabla and Z. Dong, Cisplatin nephrotoxicity: mechanisms and renoprotective strategies, Kidney Int. 73 (2008) 994-1007; https://doi.org/10.1038/sj.ki.5002786

5. P. D. Sanchez-Gonzalez, F. J. Lopez-Hernandez, J. M. Lopez-Novoa and A. I. Morales, An integrative view of the pathophysiological events leading to cisplatin nephrotoxicity, Crit. Rev. Toxicol. 41 (2011) 803-821; https://doi.org/10.3109/10408444.2011.602662

6. G. Daugaard, U. Abildgaard, N. H. Holstein-Rathlou, I. Bruunshuus, D. Bucher and P. P. Leyssac, Renal tubular function in patients treated with high-dose cisplatin, Clin. Pharmacol. Ther. 44 (1988) 164-172; https://doi.org/10.1038/clpt.1988.132

7. A. M. Abdelrahman, Y. Al Suleimani, A. Shalaby, M. Ashique, P. Manoj, A. Nemmar and B. H. Ali, Effect of canagliflozin, a sodium glucose co-transporter 2 inhibitor, on cisplatin-induced nephrotoxicity in mice, Naunyn. Schmiedebergs Arch. Pharmacol. (2018); https://doi.org/10.1007/s00210-0181564-7

8. G. J. Dugbartey, L. J. Peppone and I. A. de Graaf, An integrative view of cisplatin-induced renal and cardiac toxicities: Molecular mechanisms, current treatment challenges and potential protective measures, Toxicology 371 (2016) 58-66; https://doi.org/10.1016/j.tox.2016.10.001

9. C. N. Sharp and L. J. Siskind, Developing better mouse models to study cisplatin-induced kidney injury, Am. J. Physiol. Renal Physiol. 313 (2017) F835-f841; https://doi.org/10.1152/ajprenal.00285.2017

10. M. Hurst and B. Jarvis, Perindopril: an updated review of its use in hypertension, Drugs 61 (2001) 867-896; https://doi.org/10.2165/00003495-200161060-00020

11. P. A. Todd and A. Fitton, Perindopril. A review of its pharmacological properties and therapeutic use in cardiovascular disorders, Drugs 42 (1991) 90-114; https://doi.org/10.2165/00003495199142010-00006

12. E. M. de Cavanagh, F. Inserra and L. Ferder, Angiotensin II blockade: a strategy to slow ageing by protecting mitochondria?, Cardiovasc Res. 89 (2011) 31-40; https://doi.org/10.1093/cvr/cvq285

13. E. A. M. El-Shoura, B. A. S. Messiha, S. M. Z. Sharkawi and R. A. M. Hemeida, Perindopril ameliorates lipopolysaccharide-induced brain injury through modulation of angiotensin-II/angiotensin-1-7 and related signaling pathways, Eur. J. Pharmacol. 834 (2018) 305-317; https://doi.org/10.1016/j. ejphar.2018.07.046

14. N. E. Mohammed, B. A. Messiha and A. A. Abo-Saif, Effect of amlodipine, lisinopril and allopurinol on acetaminophen-induced hepatotoxicity in rats, Saudi Pharm. J. 24 (2016) 635-644; https:// doi.org/10.1016/j.jsps.2015.04.004

15. M. M. Abdel-Fattah, A. A. Salama, B. A. Shehata and I. E. Ismaiel, The potential effect of the angiotensin II receptor blocker telmisartan in regulating OVA-induced airway remodeling in experimental rats, Pharmacol. Rep. 67 (2015) 943-951; https://doi.org/10.1016/j.pharep.2015.02.010

16. M. G. Fahmy Wahba, B. A. Shehata Messiha and A. A. Abo-Saif, Ramipril and haloperidol as promising approaches in managing rheumatoid arthritis in rats, Eur. J. Pharmacol. 765 (2015) 30715; https://doi.org/10.1016/j.ejphar.2015.08.026

17. F. Barutta, S. Bellini, R. Mastrocola, R. Gambino, F. Piscitelli, V. di Marzo, B. Corbetta, V. K. Vemuri, A. Makriyannis, L. Annaratone, L. Annaratone, G. Bruno and G. Gruden, Reversal of albuminuria by combined AM6545 and perindopril therapy in experimental diabetic nephropathy, $\mathrm{Br}$. J. Pharmacol. 175 (2018) 4371-4385; https://doi.org/10.1111/bph.14495

18. X. M. Gao, A. Tsai, A. Al-Sharea, Y. Su, S. Moore, L. P. Han, H. Kiriazis, A. M. Dart, A. J. Murphy and X. J. Du, Inhibition of the renin-angiotensin system post myocardial infarction prevents inflammation-associated acute cardiac rupture, Cardiovasc. Drugs Ther. 31 (2017) 145-156; https://doi. org/10.1007/s10557-017-6717-2 
19. K. K. Filipski, R. H. Mathijssen, T. S. Mikkelsen, A. H. Schinkel and A. Sparreboom, Contribution of organic cation transporter 2 (OCT2) to cisplatin-induced nephrotoxicity, Clin. Pharmacol. Ther. 86 (2009) 396-402; https://doi.org/10.1038/clpt.2009.139

20. F. A. Suliman, D. M. Khodeer, A. Ibrahiem, E. T. Mehanna, M. K. El-Kherbetawy, H. M. F. Mohammad, S. A. Zaitone and Y. M. Moustafa, Renoprotective effect of the isoflavonoid biochanin A against cisplatin induced acute kidney injury in mice: Effect on inflammatory burden and p53 apoptosis, Int. Immunopharmacol. 61 (2018) 8-19; https://doi.org/10.1016/j.intimp.2018.05.010

21. A. S. Shalkami, M. I. A. Hassan and A. A. Abd El-Ghany, Perindopril regulates the inflammatory mediators, NF-kappaB/TNF-alpha/IL-6, and apoptosis in cisplatin-induced renal dysfunction, Naunyn. Schmiedebergs Arch. Pharmacol. 391 (2018) 1247-1255; https://doi.org/10.1007/s00210-0181550-0

22. I. Rubera, C. Duranton, N. Melis, M. Cougnon, B. Mograbi and M. Tauc, Role of CFTR in oxidative stress and suicidal death of renal cells during cisplatin-induced nephrotoxicity, Cell Death Dis. 4 (2013) e817; https://doi.org/10.1038/cddis.2013.355

23. H. Soni, D. Kaminski, R. Gangaraju and A. Adebiyi, Cisplatin-induced oxidative stress stimulates renal Fas ligand shedding, Ren. Fail. 40 (2018) 314-322; https://doi.org/10.1080/0886022x.2018.1456938

24. R. Goel, S. A. Bhat, K. Hanif, C. Nath and R. Shukla, Perindopril attenuates lipopolysaccharideinduced amyloidogenesis and memory impairment by suppression of oxidative stress and RAGE activation, ACS Chem. Neurosci. 7 (2016) 206-217; https://doi.org/10.1021/acschemneuro.5b00274

25. A. Dandekar, R. Mendez and K. Zhang, Cross talk between ER stress, oxidative stress, and inflammation in health and disease, Methods Mol. Biol. 1292 (2015) 205-14; https://doi.org/10.1007/978-14939-2522-3_15

26. F. Sesti, O. E. Tsitsilonis, A. Kotsinas and I. P. Trougakos, Oxidative stress-mediated biomolecular damage and inflammation in tumorigenesis, In Vivo 26 (2012) 395-402.

27. K. Hasegawa, S. Wakino, K. Yoshioka, S. Tatematsu, Y. Hara, H. Minakuchi, N. Washida, H. Tokuyama, K. Hayashi and H. Itoh, Sirt1 protects against oxidative stress-induced renal tubular cell apoptosis by the bidirectional regulation of catalase expression, Biochem. Biophys. Res. Commun. 372 (2008) 51-56; https://doi.org/10.1016/j.bbrc.2008.04.176

28. M. H. Hassan, S. A. Bahashawan, T. M. Abdelghany, G. M. Abd-Allah and M. M. Ghobara, Crocin abrogates carbon tetrachloride-induced renal toxicity in rats via modulation of metabolizing enzymes and diminution of oxidative stress, apoptosis, and inflammatory cytokines, J. Biochem. Mol. Toxicol. 29 (2015) 330-339; https://doi.org/10.1002/jbt.21702

29. J. Y. Kim, J. H. Park, K. Kim, J. Jo, J. Leem and K. K. Park, Pharmacological inhibition of caspase-1 ameliorates cisplatin-induced nephrotoxicity through suppression of apoptosis, oxidative stress, and inflammation in mice, Mediators Inflamm. 2018(2018)6571676; https://doi.org/10.1155/2018/6571676

30. J. L. Martindale and N. J. Holbrook, Cellular response to oxidative stress: signaling for suicide and survival, J. Cell Physiol. 192 (2002) 1-15; https://doi.org/10.1002/jcp.10119

31. G. Nunez, M. A. Benedict, Y. Hu and N. Inohara, Caspases: the proteases of the apoptotic pathway, Oncogene 17 (1998) 3237-3245; https://doi.org/10.1038/sj.onc.1202581

32. E. A. Slee, M. T. Harte, R. M. Kluck, B. B. Wolf, C. A. Casiano, D. D. Newmeyer, H. G. Wang, J. C. Reed, D. W. Nicholson, E. S. Alnemri, D. R. Green and S. J. Martin, Ordering the cytochrome c-initiated caspase cascade: hierarchical activation of caspases-2, -3, -6, -7, -8, and -10 in a caspase-9-dependent manner, J. Cell Biol. 144 (1999) 281-292; https://doi.org/10.1083/jcb.144.2.281 